\title{
WIND SPEED ANALYSIS AT IKEJA, NIGERIA USING THE CONVENTIONAL PROBABILITY DENSITY FUNCTIONS
}

\author{
OLUSEYI OGUNSOLA ${ }^{* 1}$, OFURE OSAGIEDE ${ }^{1}$ \\ ${ }^{1}$ Department of Physics, University of Ibadan, Ibadan, Nigeria
}

\begin{abstract}
The wind energy potential at Ikeja (Lat. $6.35^{\circ} \mathrm{N}$; Long. $3.20^{\circ} \mathrm{E}$ ), Nigeria was statistically analyzed using three of the mostly utilized conventional Probability Distribution Functions (PDFs) in order to determine which of these distributions would give the best means of analysis for wind in this particular location. The best fit test for these PDFs were determined from Akaike Information Criteria, Bayesian Information Criteria, KolmogorovSmirnov test, Cramer-von Mises statistics, Anderson-Darling Statistic, Mean Square Error and Chi-Square Test using Maximum Likelihood Estimation and Method of Moments as parameter estimates. The Weibull distribution gave the best fit in this location.
\end{abstract}

Keywords: weibull distribution, probability distribution functions, maximum likelihood estimator, method of moment, parameter estimates and best fit

\section{INTRODUCTION}

Wind is a renewable form of energy which is abundant in many parts of the world [1].The reasons for the development of wind as a renewable source of energy include higher demand and decline in fossil fuel reserves including the global warming issues associated with the fossil fuel utilization [2]. Wind speed which is the movement of air in the atmosphere at a particular time is a random variable and is usually measured using anemometer. The easiest and most direct means of determining wind speed distributions in different locations is to set up a measurement station at each location with facilities, instruments and equipment's for observing this important atmospheric parameter which could be used to provide reliable information for weather forecasts and to study weather and climate [3].

The modeling of wind speed variation is an essential requirement in the estimation of wind energy for any particular location [4]. In the earlier works on statistical modeling of wind speed variation, much consideration has been given to the two-parameter Weibull distribution (shape parameter and scale parameter) because it has been found to fit a wide collection of wind data [5]. For example, in the evaluation of wind energy potential in Nigeria, the Weibull distribution has been well utilized [6-11]. The dimensionless shape parameter describes how the data are distributed, while the scale parameter defines the position of the Weibull curve relative to the threshold [12]. However, other probability density functions apart from that of Weibull including Gamma and Lognormal shall also be included in the analysis utilized in this work in order to be able to determine how well they too could accurately fit the wind speed data in this location.

\subsection{Weibull distribution}

The two-parameter Weibull distribution (shape parameter, $\mathrm{k}$ and scale parameter, $\mathrm{c}$ ) has been widely applied by many researchers in statistical modeling of wind speed variation [5-11]. The probability density function of the Weibull distribution was given as:

\footnotetext{
${ }^{*}$ Corresponding author, e-mail: seyiogunsola22@ gmail.com

(c) 2018 Alma Mater Publishing House
} 


$$
f(v)=\left(\frac{k}{c}\right)\left(\frac{v}{c}\right)^{k-1} \exp \left[\left(-\frac{v}{c}\right)^{k}\right]
$$

Where: $f(\boldsymbol{v})$ is Probability of the observed wind speed; $\mathrm{k}$ - shape parameter; $\mathrm{c}$ - scale parameter; $\boldsymbol{v}$ - wind speed.

The corresponding cumulative distribution function of the Weibull distribution [13] was given as:

$$
F(v)=1-\exp \left[-\left(\frac{v}{c}\right)^{k}\right]
$$

\subsection{Gamma distribution}

The probability density function of gamma for wind speed, $v$, with two parameters was given by [14] as:

$$
f(v, \alpha, \beta)=\frac{v^{\alpha-1}}{\beta^{\alpha} \Gamma(\alpha)} \exp \left[-\frac{v}{\beta}\right]
$$

where: $\alpha$ is shape parameter; $\beta$ - scale parameter; $\Gamma$-gamma function; $v$-wind speed.

The cumulative distribution function of gamma [15] was also expressed as:

$$
f(x, k, \theta)=\frac{1}{\theta^{k} \Gamma(k)} x^{k-1} \exp \left(-\frac{x}{\theta}\right)
$$

where: $\mathrm{K}$ is shape parameter; $\theta$ - scale parameter; $\Gamma$-gamma function; $x$-value at which wind speed is estimated.

\subsection{Lognormal distribution}

The probability density function of lognormal distribution [16] was given as:

$$
f(v, \mu, \sigma)=\frac{1}{v \sigma \sqrt{2 \pi}} \exp \left\{-\frac{1}{2}\left(\frac{\ln (v)-\mu}{\sigma}\right)^{2}\right\}
$$

where: $\sigma$ is shape parameter; $\mu$-scale parameter; $\boldsymbol{v}$ - wind speed.

The cumulative distribution function was also expressed as:

$$
F(v, \mu, \sigma)=\frac{1}{2}+\frac{1}{2} \operatorname{erf}\left[\frac{\ln (v)-\mu}{\sigma \sqrt{2}}\right]
$$

where the error function "erf" is defined as:

$$
\operatorname{erf}(v)=\frac{2}{\sqrt{\pi}} \int \exp \left(-t^{2}\right) d t
$$




\section{METHODOLOGY}

Wind speed data at a height of $10 \mathrm{~m}$ obtained from the Nigerian Meteorological Agency (NIMET), Lagos for Ikeja (Lat. $6.35^{\circ} \mathrm{N}$; Long. $3.20^{\circ} \mathrm{E}$ ), which is one of the coastal areas in Nigeria where wind speeds were deemed to be highest in the southern region of the country, were analyzed using statistical approach including three of the conventional probability density functions (Weibull, Gamma and Lognormal distribution). The distribution that gives the best fit for the wind speed data in this location were also determined using various methods of goodness of fit tests which are based on Empirical distribution functions.

\subsection{Goodness of fit tests}

The evaluation of the goodness of fit test is a very important process in the determination of the best distribution. The goodness of fit measures the compatibility of a random sample with a theoretical probability distribution function [17]. Seven different types of goodness of fit tests were utilized in this work to determine the best distribution function for the wind data at Ikeja which include: Akaike Information Criteria (AIC), Bayesian information criteria (BIC), Kolmogorov-Smirnov test (KS), Cramer-von Mises statistic (CvMs), AndersonDarling Statistic (ADS), Mean Square Error (MSE) and Chi-Square Statistic $\left(\chi^{2}\right)$.

\subsubsection{Akaike Information Criteria (AIC)}

AIC is usually used to measure the goodness of fit for a statistical model and also provides the means for comparison among models. The model with the minimum AIC value gives the best fit [18] and was given as:

$$
A I C=-2 \log (L)+2 k
$$

where: $\mathrm{L}$ is likelihood; $k$ - number of parameter in the fitted model.

\subsubsection{Bayesian Information Criteria (BIC)}

The BIC is closely related to AIC and it chooses the model with the highest probability by using the Bayesian frame work. The BIC is also known as Schwarz's Bayesian Criterion (SBC) and the model with the minimum BIC value gives the best model fit of the parameters estimated [18] as:

$$
\mathrm{BIC}=-2 \log (\mathrm{L})+\mathrm{k} \log (\mathrm{n})
$$

where: $\mathrm{L}$ is likelihood; $\mathrm{k}$ - number of parameters; $\mathrm{n}$ - number of observations in the fitted model.

\subsubsection{Kolmogorov-Smirnov test (K-S test)}

The K-S test is based on the maximum difference between the hypothetical and the empirical cumulative distributions $\left(\mathrm{F}_{\mathrm{E}}\right)$ and if the result of the test is lower than a critical value, the fit to the distribution is considered to be good [19], with the minimum value selected as the best since it will indicate that the samples are drawn from the same distribution. The K-S test was originally presented as a goodness of fit test by [20] together with a critical value table. The empirical cumulative probability distributions function was given as:

$$
F_{E}(x)=\frac{1}{n}[E(i)]
$$

where: $\mathrm{E}(\mathrm{i})$ is number of points smaller than $\mathrm{x}$, with $\mathrm{x}$ values sorted from smallest to largest; $\mathrm{n}$ - number of data points.

\subsubsection{Cramer-von Mises statistics (CvMs)}

The CvMs is a criterion for judging the goodness of fit of a cumulative distribution function when compared to a given empirical distribution function, or for comparing two empirical distributions [21] and was given as:

$$
w^{2}=\int_{-\infty}^{\infty}\left[F_{n}(x)-F^{*}(x)\right]^{2} d F^{*}(x)
$$


where: $w^{2}$ is Cramer-von Mises statistics; $F^{*}$ - theoretical distribution; $F_{n}$ - the empirical observed distribution; $d F^{*}$ - differential of the theoretical distribution.

\subsubsection{The Anderson - Darling Statistic (ADS)}

The ADS is a general test to compare the fit of an observed cumulative distribution function [22]. This test gives more weight to the tails than the K-S test and was given as:

$$
A D=-n-\frac{1}{n} \sum_{i=1}^{n}(2 i-1)\left[\ln F\left(X_{i}\right)+\ln \left(1-F\left(X_{n-i+1}\right)\right)\right]
$$

where: $\mathrm{n}$ is the sample size; $F(X)$ - cumulative distribution function for the specified distribution; $\mathrm{i}$ - the ith sample, calculated when the data is sorted in ascending order.

\subsubsection{Mean Square Error (MSE)}

The MSE or mean squared deviation of an estimator measures the average of the squares of the errors or deviation, that is the difference between the estimator and what is estimated [23]. It is always non negative and the values that are closer to zero are taken as being better. MSE are generally written as:

$$
M S E=\frac{1}{n} \sum_{i=1}^{n}\left(y_{i}-y_{i}\right)^{2}
$$

where: $\mathrm{n}$ is number of observations; $y_{i}$ - value returned by the model; $\bar{y}_{i}$ - actual value for data point $\mathrm{i}$.

\subsubsection{Chi-Square Test $\left(\chi^{2}\right)$}

Chi-Square Test was used to determine if a sample comes from a population with a specific distribution [17]. This test is applied to binned data, so the value of the test statistic depends on how the data is binned. This test is available for continuous sample data only and is given as:

$$
\chi^{2}=\sum_{i=1}^{k} \frac{\left(O_{i}-E_{i}\right)^{2}}{E_{i}}
$$

where: $O_{i}$ is observed frequency for bin i; $E_{i}$ - expected frequency for bin i calculated by:

$$
E_{i}=F\left(x_{2}\right)-F\left(x_{1}\right)
$$

where: $\mathrm{F}$ - cumulative distribution functions of the probability distribution being tested; $x_{i}, x_{2}$ are limits for bin i.

\subsection{Parameter estimation}

There are a number of well-known methods which can be used to estimate distribution parameters based on available sample data [24].

The methods used for the estimation of distribution of parameters for the Weibull, Gamma and Lognormal distributions utilized in the analysis of the wind speed data analyzed in this work are the Maximum likelihood Estimates (MLE) and Method of Moments (MOM).

\subsubsection{Weibull shape and scale parameters based on MLE}

The MLE Weibull shape and scale parameters [25] were computed as: 


$$
\begin{gathered}
k=\left[\frac{\sum_{i=1}^{n} v_{i}^{k} \ln \left(v_{i}\right)}{\sum_{i=1}^{n} v_{i}^{k}}-\frac{\sum_{i=1}^{n} \ln \left(v_{i}\right)}{n}\right]^{-1} \\
c=\left[\frac{\sum_{i=1}^{n} v_{i}^{k}}{n}\right]^{\frac{1}{k}}
\end{gathered}
$$

where: $\mathrm{k}$ is shape parameter; $\mathrm{c}$ - scale parameter; $v_{i}$ - wind speed in time step; $\mathrm{n}$ - the number of non-zero wind speed data.

\subsubsection{Weibull shape and scale parameters based on MOM}

The Weibull shape and scale parameters based on MOM [26] were computed as:

$$
\begin{gathered}
k=\left(0.9874 / \frac{\bar{v}}{\sqrt{S^{2}}}\right)^{1.0983} \\
c=\frac{\bar{v}}{\Gamma\left(1+\frac{1}{k}\right)}
\end{gathered}
$$

where: $\mathrm{k}$ is shape parameter; $\mathrm{c}$ - scale parameter; $\bar{v}$ - mean wind speed; $\mathrm{S}^{2}$ - wind speed variance; $\Gamma$ - gamma function.

The wind speed variance formula can also be presented as:

$$
S^{2}=\frac{\sum(v-\bar{v})}{n-1}
$$

where $\mathrm{n}$ is the number of samples.

\subsubsection{Gamma shape and scale parameters based On MLE}

The Gamma shape and scale parameters based on the MLE [24] were computed by simultaneously solving the following equations:

$$
\begin{gathered}
\alpha \beta=\bar{v} \\
n \ln (\beta)+n \psi(\alpha)=\sum_{i=1}^{n} \ln \left(v_{i}\right)
\end{gathered}
$$

where: $\mathrm{n}$ is number of samples; $\psi$ - digamma function; $v_{i}$ - wind speed in time step $\mathrm{i} ; \bar{v}$ - mean wind speed; $\alpha$ - shape parameter; $\beta$ - scale parameter; 
The digamma function was also calculated using the equation:

$$
\psi(\alpha)=\frac{d}{d \alpha} \ln (\Gamma(\alpha))
$$

\subsubsection{Gamma shape and scale parameters based on MOM}

The gamma shape and scale parameters based on MOM [27] were computed in a similar way to the expressions which could be written as:

$$
\alpha=\left(\frac{-}{\bar{v}}\right)^{2}
$$

and

$$
\beta=\frac{S^{2}}{\bar{v}}
$$

where: $\alpha$ is shape parameter; $\beta$ - scale parameter; $\bar{v}$ - mean wind speed; $\mathrm{S}$ - standard deviation.

\subsubsection{Lognormal Shape and Scale parameters based On MLE}

The Lognormal shape and scale parameters based on MLE were computed according to [14, 16] as:

$$
\begin{gathered}
\sigma=\sqrt{\frac{1}{N} \sum_{i=1}^{N}\left[\ln \left(v_{i}\right)-\mu\right]^{2}} \\
\mu=\frac{1}{N} \sum_{i=1}^{N} \ln \left(v_{i}\right)
\end{gathered}
$$

where: $\mu$ is shape parameter; $\sigma$ - scale parameter; $\mathrm{N}$ - number of total data; $v_{i}$ is the $\mathrm{i}$-th value of the wind speed data.

\subsubsection{Lognormal shape and scale parameters based on MOM}

The Lognormal shape and scale parameters based on MOM [28] were computed as:

$$
\begin{aligned}
& \sigma=\sqrt{\ln \left(\sum_{i=1}^{n} v_{i}^{2}\right)-2 \ln \left(\sum_{i=1}^{n} v_{i}\right)+\ln (n)} \\
& \mu=-\frac{\ln \left(\sum_{i=1}^{n} v_{i}^{2}\right)}{2}+2 \ln \left(\sum_{i=1}^{n} v_{i}\right)-\frac{3}{2} \ln (n)
\end{aligned}
$$

where: $\mu$ is shape parameter; $\sigma$ - scale parameter; $\mathrm{n}$ - number of total data; $v_{i}$ - the $\mathrm{i}$-th value of wind speed data.

\subsection{Power density distribution and mean power density}

The wind energy, $E_{\text {wind }}[1]$ in atmospheric flow (i.e. the kinetic energy of the air, $0.5 \rho v^{2}$ advected with the wind) was given as: 


$$
E_{\text {wind }}=0.5 \rho A_{r} v^{2} v=0.5 \rho A_{r} v^{3}
$$

where, $A_{r}$ is the area of the wind rotor.

In a similar way, the wind power, $P(v)$ [5] flowing with a mean speed, $v_{m}$ through a wind rotor blade with sweep area, A was utilized [29] as:

$$
P(v)=\frac{1}{2} \rho A v_{m}^{3}
$$

where: $\rho$ is the standard air density; $v_{m}$ - mean wind speed.

However, since the mean power density, $p_{m}$ is defined as the ratio of the wind power, $P(v)$ to the area, A.

Thus,

$$
p_{m}=\frac{1}{2} \rho v_{m}^{3}
$$

where: $\rho$ is $1.2205 \mathrm{~kg} / \mathrm{m}^{3}$ at Ikeja, Nigeria.

\section{RESULTS AND DISCUSSION}

The analysis of data showed that the yearly mean wind speed for this period of study at Ikeja ranged from 7.3 $\mathrm{m} / \mathrm{s}-11.8 \mathrm{~m} / \mathrm{s}$ with an average mean wind speed of $9.5 \mathrm{~m} / \mathrm{s}$ as presented in Table 1 . Seven (7) of the years during this period of study have their mean wind speeds greater than $9.5 \mathrm{~m} / \mathrm{s}: 2007(11.4 \mathrm{~m} / \mathrm{s}), 2006(10.5 \mathrm{~m} / \mathrm{s})$, $2005(10.5 \mathrm{~m} / \mathrm{s}), 2002(10.5 \mathrm{~m} / \mathrm{s}), 2001(10.2 \mathrm{~m} / \mathrm{s}), 2004(9.9 \mathrm{~m} / \mathrm{s})$ and $2000(9.7 \mathrm{~m} / \mathrm{s})$ as shown in Figure 1.

However, the year $2009(6.7 \mathrm{~m} / \mathrm{s})$ has the least mean wind speed for this period of study. It was also observed that amongst the various months of the years considered in this study (2000-2010), the greatest wind speed occurred in August, $2007(15.4 \mathrm{~m} / \mathrm{s})$ which was also the month with the greatest mean wind speed $(11.8 \mathrm{~m} / \mathrm{s})$ for this period of study as shown in Figure 2.

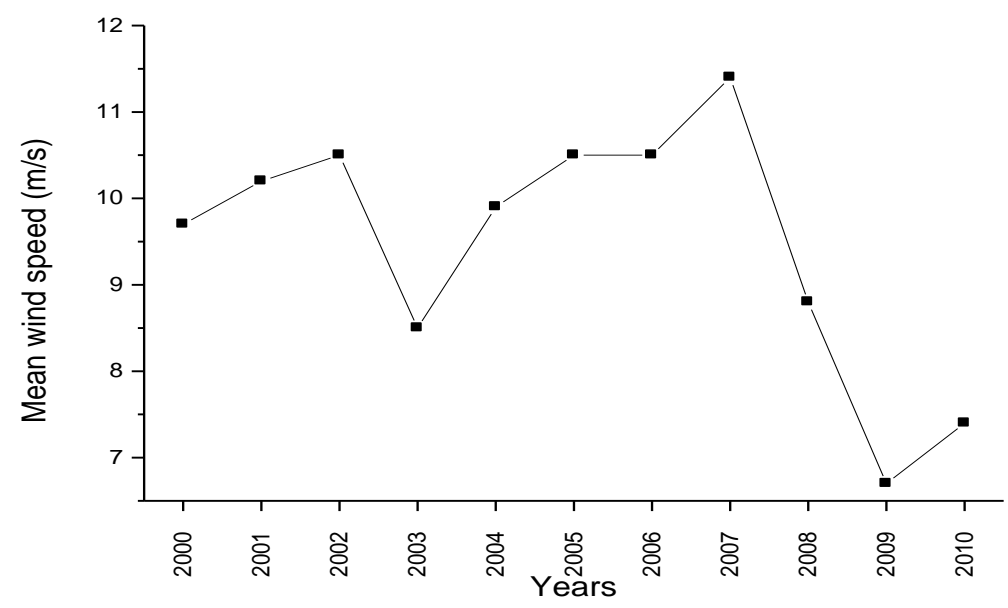

Fig. 1. Yearly mean wind speed variation at Ikeja for the period $2000-2010$. 
Table 1. Summary of mean wind speeds at Ikeja for the period $2000-2010$.

\begin{tabular}{|c|c|c|c|c|c|c|c|c|c|c|c|c|}
\hline \multirow[b]{2}{*}{ Months } & \multicolumn{11}{|c|}{ Years / wind speed $(\mathrm{m} / \mathrm{s})$} & \multirow{2}{*}{$\begin{array}{l}\text { Mean wind } \\
\text { speed }(\mathrm{m} / \mathrm{s})\end{array}$} \\
\hline & 2000 & 2001 & 2002 & 2003 & 2004 & 2005 & 2006 & 2007 & 2008 & 2009 & 2010 & \\
\hline January & 11.2 & 9.1 & 9.6 & 6.3 & 6.2 & 8.9 & 10.0 & 7.6 & 8.5 & 6.8 & 5.1 & 8.1 \\
\hline February & 8.6 & 10.5 & 11.2 & 9.0 & 10.2 & 11.3 & 11.8 & 11.9 & 10.1 & 7.4 & 8.0 & 10.0 \\
\hline March & 10.7 & 11.4 & 11.9 & 9.5 & 11.5 & 11.1 & 12.1 & 12.7 & 13.5 & 8.3 & 6.7 & 10.8 \\
\hline April & 11.4 & 10.2 & 11.1 & 8.9 & 10.8 & 12.1 & 12.7 & 14.3 & 11.6 & 8.4 & 8.0 & 10.9 \\
\hline May & 9.9 & 9.1 & 10.5 & 10.3 & 9.7 & 9.9 & 10.7 & 10.9 & 9.1 & 7.0 & 6.9 & 9.5 \\
\hline June & 8.4 & 9.0 & 10.0 & 9.7 & 10.1 & 9.6 & 7.5 & 10.4 & 8.1 & 6.3 & 5.9 & 8.6 \\
\hline July & 10.0 & 12.2 & 11.0 & 12.5 & 12.4 & 11.2 & 12.2 & 13.5 & 8.0 & 6.5 & 10.5 & 10.9 \\
\hline August & 10.5 & 11.5 & 13.0 & 10.8 & 12.3 & 12.8 & 13.2 & 15.4 & 11.1 & 8.0 & 10.9 & 11.8 \\
\hline September & 9.9 & 11.6 & 11.5 & 8.7 & 9.5 & 12.2 & 11.9 & 11.3 & 7.5 & 6.2 & 9.4 & 10.0 \\
\hline October & 9.2 & 9.2 & 8.3 & 6.7 & 9.0 & 8.8 & 9.7 & 11.3 & 6.3 & 5.5 & 7.3 & 8.3 \\
\hline November & 8.4 & 9.6 & 8.6 & 4.9 & 8.5 & 9.4 & 6.6 & 9.2 & 5.8 & 5.0 & 5.6 & 7.4 \\
\hline December & 8.2 & 9.3 & 9.7 & 4.3 & 9.4 & 8.2 & 7.5 & 7.9 & 5.5 & 5.4 & 4.8 & 7.3 \\
\hline $\begin{array}{l}\text { Mean } \\
(\mathrm{m} / \mathrm{s})\end{array}$ & 9.7 & 10.2 & 10.5 & 8.5 & 9.9 & 10.5 & 10.5 & 11.4 & 8.8 & 6.7 & 7.4 & 9.5 \\
\hline
\end{tabular}

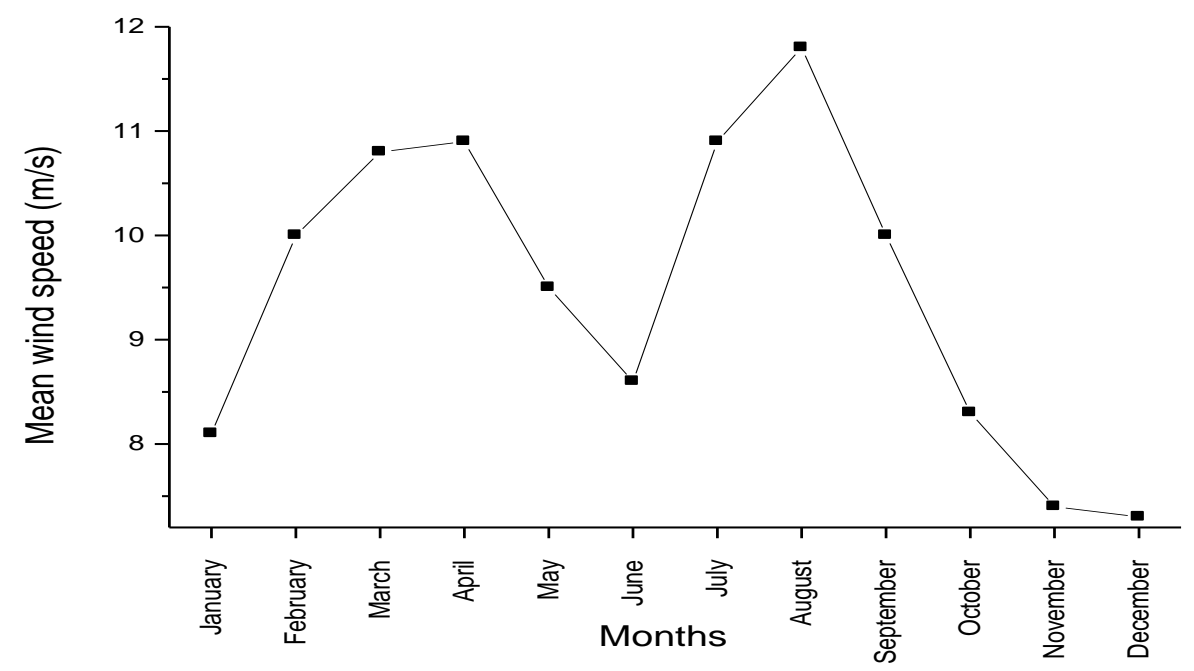

Fig. 2. Monthly mean wind speed variation at Ikeja for the period $2000-2010$.

The yearly mean wind speed range of $5.6 \mathrm{~m} / \mathrm{s}$ was also observed for this period of study as presented in Table 2 and six (6) of the years has a mean wind speed range greater than this value: $2003(8.2 \mathrm{~m} / \mathrm{s}), 2008(8.0 \mathrm{~m} / \mathrm{s})$, $2007(7.8 \mathrm{~m} / \mathrm{s}), 2006(6.6 \mathrm{~m} / \mathrm{s}), 2004(6.2 \mathrm{~m} / \mathrm{s})$ and $2010(6.1 \mathrm{~m} / \mathrm{s})$. However, a monthly mean wind speed range of $5.4 \mathrm{~m} / \mathrm{s}$ was observed as presented in Table 3 for this period of study, with five (5) of these months having a mean wind speed range greater than this value: August $(7.4 \mathrm{~m} / \mathrm{s})$, March $(6.8 \mathrm{~m} / \mathrm{s})$, January $(6.1 \mathrm{~m} / \mathrm{s})$, July $(6.0$ $\mathrm{m} / \mathrm{s})$ and September $(6.0 \mathrm{~m} / \mathrm{s})$ as shown in Figure 3. 
Table 2. Summary of yearly mean wind Speed range at Ikeja for the period 2000 - 2010.

\begin{tabular}{|l|c|c|c|}
\hline Years & $\begin{array}{c}\text { Minimum } \\
\text { wind speed } \\
(\mathrm{m} / \mathrm{s})\end{array}$ & $\begin{array}{c}\text { Maximum wind } \\
\text { speed } \\
(\mathrm{m} / \mathrm{s})\end{array}$ & $\begin{array}{c}\text { Wind speed } \\
\text { range } \\
(\mathrm{m} / \mathrm{s})\end{array}$ \\
\hline 2000 & 8.2 & 11.4 & 3.2 \\
\hline 2001 & 9.0 & 12.2 & 3.0 \\
\hline 2002 & 8.3 & 13 & 4.7 \\
\hline 2003 & 4.3 & 12.5 & 8.2 \\
\hline 2004 & 6.2 & 12.4 & 6.2 \\
\hline 2005 & 8.2 & 12.8 & 4.6 \\
\hline 2006 & 6.6 & 13.2 & 6.6 \\
\hline 2007 & 7.6 & 15.4 & 7.8 \\
\hline 2008 & 5.5 & 13.5 & 8.0 \\
\hline 2009 & 5.0 & 8.4 & 3.4 \\
\hline 2010 & 4.8 & 10.9 & 6.1 \\
\hline Mean $(\mathrm{m} / \mathrm{s})$ & 6.7 & 12.3 & 5.6 \\
\hline
\end{tabular}

Table 3. Summary of monthly mean wind speed range at Ikeja for the period $2000-2010$.

\begin{tabular}{|l|c|c|c|}
\hline Month & $\begin{array}{c}\text { Minimum } \\
\text { wind speed } \\
(\mathrm{m} / \mathrm{s})\end{array}$ & $\begin{array}{c}\text { Maximum } \\
\text { wind speed } \\
(\mathrm{m} / \mathrm{s})\end{array}$ & $\begin{array}{c}\text { Wind speed } \\
\text { range } \\
(\mathrm{m} / \mathrm{s})\end{array}$ \\
\hline January & 5.1 & 11.2 & 6.1 \\
\hline February & 7.4 & 11.9 & 4.5 \\
\hline March & 6.7 & 13.5 & 6.8 \\
\hline April & 8.0 & 12.7 & 4.7 \\
\hline May & 6.9 & 10.9 & 4.0 \\
\hline June & 5.9 & 10.4 & 4.5 \\
\hline July & 6.5 & 12.5 & 6.0 \\
\hline August & 8.0 & 15.4 & 7.4 \\
\hline September & 6.2 & 12.2 & 6.0 \\
\hline October & 6.5 & 11.3 & 4.8 \\
\hline November & 4.9 & 9.6 & 4.7 \\
\hline December & 4.3 & 9.7 & 5.4 \\
\hline Mean $(\mathrm{m} / \mathrm{s})$ & 6.4 & 11.8 & 5.4 \\
\hline
\end{tabular}

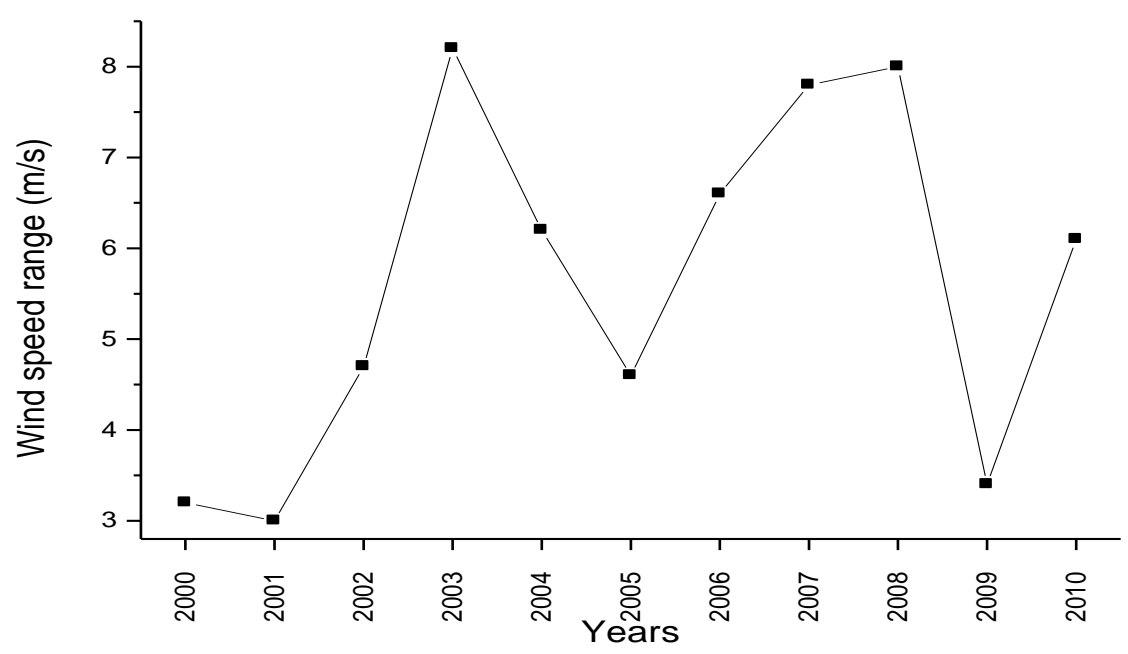

Fig. 3. Wind speed range at Ikeja for the period $2000-2010$. 
The results of the various methods of determining the goodness of fit tests for the conventional Probability Density Functions (PDFs) showed that the Weibull distribution gave the best estimates in terms of efficiency of performance amongst the three (3) distributions considered. The Weibull distribution performed best for AIC, BIC, KS and CvMs by having the least values from the Maximum Likelihood Estimation (MLE) and also performed best for $\chi^{2}$ with the least value for the Method of Moments (MOM).

The log-normal only performed best for MSE when MOM was utilized due to the fact that the value obtained for the scale parameter was less than 1 (one) as presented in Table 4. This result showed that it was Weibull distribution that gave the best fit in this location, followed by the gamma distribution, while the lognormal distribution had the least performance. This was due to the fact that gamma distribution appears to have the next least errors to Weibull distribution in all the methods used to evaluate the goodness of fit tests except in MSE.

Table 4. Estimates efficiency and goodness of fit for the three conventional probability distribution functions utilized in this Study.

\begin{tabular}{|c|c|c|c|c|c|c|c|c|c|}
\hline \multirow[b]{2}{*}{ Distribution } & \multirow[b]{2}{*}{ Methods } & \multicolumn{7}{|c|}{ Statistics } & \multirow[b]{2}{*}{ Remarks } \\
\hline & & $\chi^{2}$ & AIC & BIC & $\mathrm{KS}$ & CvMS & ADS & MSE & \\
\hline \multirow{2}{*}{ Weibull } & MLE & 9.1049 & 590.6250 & 596.3910 & 0.0357 & 0.0202 & 0.1869 & 0.0380 & \multirow{2}{*}{ BEST } \\
\hline & MOM & 9.0796 & 590.7130 & 596.4230 & 0.2847 & 0.0212 & 0.1000 & 0.0380 & \\
\hline \multirow{2}{*}{ Gamma } & MLE & 19.0596 & 599.3060 & 605.0720 & 0.0749 & 0.1926 & 1.2350 & 0.0710 & \multirow{2}{*}{ BETTER } \\
\hline & MOM & 22.39426 & 599.9240 & 605.6900 & 0.0697 & 0.1934 & 1.3704 & 0.0760 & \\
\hline \multirow{2}{*}{ Lognormal } & MLE & 26.0739 & 606.3570 & 612.1230 & 0.0923 & 0.3010 & 1.8818 & 0.0354 & \multirow{2}{*}{ GOOD } \\
\hline & MOM & 40.1257 & 609.1010 & 614.8660 & 0.0827 & 0.3004 & 2.2760 & 0.0351 & \\
\hline
\end{tabular}

The monthly values for the shape (k) and scale (c) parameters for Weibull distribution using MLE are 4.8 and $10.3 \mathrm{~m} / \mathrm{s}$ respectively, while the yearly values for both $\mathrm{k}$ and $\mathrm{c}$ parameters were 8.9 and $10.0 \mathrm{~m} / \mathrm{s}$ respectively. Also, the monthly values for $\mathrm{k}$ and $\mathrm{c}$ Parameters for the Weibull distribution using MOM are 4.8 and $10.3 \mathrm{~m} / \mathrm{s}$ respectively, while the yearly values for these $\mathrm{k}$ and $\mathrm{c}$ parameters were 7.8 and $10.1 \mathrm{~m} / \mathrm{s}$ respectively as presented in Table 5. The monthly values for $\mathrm{k}$ and $\mathrm{c}$ parameters for the gamma distribution using MLE are 1.61 and $1.7 \mathrm{~m} / \mathrm{s}$ respectively, while the yearly values for both $\mathrm{k}$ and $\mathrm{c}$ were 43.3 and $4.6 \mathrm{~m} / \mathrm{s}$ respectively.

Table 5. Parameters of the Weibull distribution for the period of study.

\begin{tabular}{|c|c|c|c|}
\hline \multirow{2}{*}{ Methods } & Parameters & Values (Monthly) & Values (Yearly) \\
\hline \multirow{2}{*}{ MLE } & Shape $=\mathrm{k}$ & 4.8 & 8.9 \\
\cline { 2 - 4 } & Scale $=\mathrm{c}$ & $10.3 \mathrm{~m} / \mathrm{s}$ & $10.0 \mathrm{~m} / \mathrm{s}$ \\
\hline \multirow{2}{*}{ MOM } & Shape $=\mathrm{k}$ & 4.8 & 7.8 \\
\cline { 2 - 4 } & Rate $=\mathrm{c}$ & $10.3 \mathrm{~m} / \mathrm{s}$ & $10.1 \mathrm{~m} / \mathrm{s}$ \\
\hline
\end{tabular}

Also, the monthly values for $\mathrm{k}$ and c parameters for the gamma distribution using MOM are 17.7 and $1.9 \mathrm{~m} / \mathrm{s}$ respectively, while the yearly values for these $\mathrm{k}$ and $\mathrm{c}$ parameters were 47.3 and $5.0 \mathrm{~m} / \mathrm{s}$ respectively as presented in Table 6. The monthly values for $\mathrm{k}$ and $\mathrm{c}$ parameters for the log-normal distribution using MLE are 2.2 and $0.3 \mathrm{~m} / \mathrm{s}$ respectively, while the yearly values of both $\mathrm{k}$ and c were 2.2 and $0.2 \mathrm{~m} / \mathrm{s}$ respectively. Also the monthly values for $\mathrm{k}$ and $\mathrm{c}$ parameters for the log-normal distribution using MOM are 2.2 and $0.2 \mathrm{~m} / \mathrm{s}$ respectively, while the yearly values for these $\mathrm{k}$ and c parameters were 2.2 and $0.2 \mathrm{~m} / \mathrm{s}$ respectively, which are the same as their monthly values as presented in Table 7.

Table 6. Parameters of the gamma distribution for the period of study.

\begin{tabular}{|l|l|l|l|}
\hline Methods & Parameters & Values (Monthly) & Values (Yearly) \\
\hline \multirow{3}{*}{ MLE } & Shape $=\alpha$ & 16.1 & 43.3 \\
\cline { 2 - 4 } & Scale $=\beta$ & $1.7 \mathrm{~m} / \mathrm{s}$ & $4.6 \mathrm{~m} / \mathrm{s}$ \\
\hline \multirow{3}{*}{ MOM } & Shape $=\alpha$ & 17.7 & 47.3 \\
\cline { 2 - 4 } & Scale $=\beta$ & $1.9 \mathrm{~m} / \mathrm{s}$ & $5.0 \mathrm{~m} / \mathrm{s}$ \\
\hline
\end{tabular}


Table 7. Parameters of the lognormal distribution for the period of study.

\begin{tabular}{|l|l|l|l|}
\hline Methods & Parameters & Values (Monthly) & Values (Yearly) \\
\hline \multirow{2}{*}{ MLE } & Shape $=\mu$ & 2.2 & 2.2 \\
\cline { 2 - 4 } & Scale $=\sigma$ & $0.3 \mathrm{~m} / \mathrm{s}$ & $0.2 \mathrm{~m} / \mathrm{s}$ \\
\hline \multirow{2}{*}{ MOM } & Shape $=\mu$ & 2.2 & 2.2 \\
\cline { 2 - 4 } & Scale $=\sigma$ & $0.2 \mathrm{~m} / \mathrm{s}$ & $0.2 \mathrm{~m} / \mathrm{s}$ \\
\hline
\end{tabular}

The mean power density for Ikeja was calculated using equation 31 as presented in Table 8 . The mean monthly mean power density showed a range of $237.4-1002.7 \mathrm{~W} / \mathrm{m}^{2}$ with the month of August having the highest mean power density value and the month of December having the least value as shown in Figure 4. The mean power density potential for Ikeja from an average mean speed of $9.5 \mathrm{~m} / \mathrm{s}$ was calculated as $553.5 \mathrm{~W} / \mathrm{m}^{2}$ for the period of this study.

Table 8. Mean wind speed and power density $\left(\mathrm{W} / \mathrm{m}^{2}\right)$ at Ikeja for the period of study (2000-2010).

\begin{tabular}{|l|c|c|}
\hline Months & $\begin{array}{c}\text { Mean wind speed } \\
(\mathrm{m} / \mathrm{s})\end{array}$ & $\begin{array}{c}\text { Mean Power } \\
\text { Density }\left(\mathrm{W} / \mathrm{m}^{2}\right)\end{array}$ \\
\hline January & 8.1 & 324.3 \\
\hline February & 10.0 & 610.3 \\
\hline March & 10.8 & 768.7 \\
\hline April & 10.9 & 790.3 \\
\hline May & 9.5 & 523.2 \\
\hline June & 8.6 & 388.2 \\
\hline July & 10.9 & 790.3 \\
\hline August & 11.8 & 1002.7 \\
\hline September & 10.0 & 610.3 \\
\hline October & 8.3 & 348.9 \\
\hline November & 7.4 & 247.3 \\
\hline December & 7.3 & 237.4 \\
\hline $\begin{array}{l}\text { Mean for the period } \\
\text { of Study }\end{array}$ & 9.5 & 553.5 \\
\hline
\end{tabular}

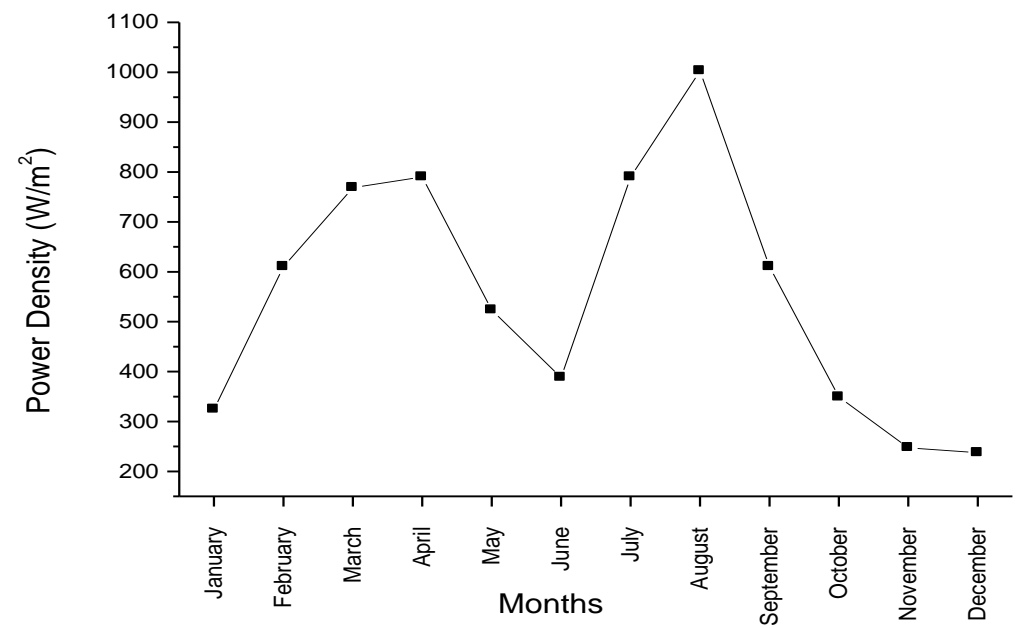

Fig. 4. Monthly variation of wind power density at Ikeja for the period $2000-2010$. 


\section{CONCLUSION}

The wind speed data at Ikeja were analyzed using statistical approach including the 2-parameter Weibull distribution (shape parameter and scale parameter), gamma distribution and lognormal distribution. Amongst these three distributions the one that gives the best fit for the wind speed data was also determined using various methods of goodness of fit tests including Akaike Information Criteria, Bayesian Information Criteria, Kolmogorov-Smirnov test, Cramer-von Mises Statistics, Anderson Darling Statistic, Mean Square Error and Chi-square Test.

The yearly mean wind speed value obtained for Ikeja during the period of study was $9.5 \mathrm{~m} / \mathrm{s}$ with the year 2007 having the highest mean wind speed $(11.4 \mathrm{~m} / \mathrm{s})$ and the year $2009(6.7 \mathrm{~m} / \mathrm{s})$ with the least mean wind speed. Also, the month with the greatest mean wind speed occurrence was August, $2007(15.4 \mathrm{~m} / \mathrm{s})$.

The results of the various methods of determining the goodness of fit tests for the conventional Probability Density Functions (PDFs) showed that the Weibull distribution gave the best estimates in terms of efficiency of performance amongst the three (3) distributions considered. It also performed best for AIC, BIC, KS and CvMs using the Maximum Likelihood Estimation.

The value of the mean power density calculated for the mean wind speed at Ikeja on monthly basis showed a range of $237.4-1002.7 \mathrm{~W} / \mathrm{m}^{2}$ with the month of August having the highest mean power density value, while the month of December had the least value. This showed that the wind power class for Ikeja varies from class 4 to 8 [30]. However, the mean power density potential for this location was obtained as $553.5 \mathrm{~W} / \mathrm{m}^{2}$ for the period of this study and this area could be classified as been suitable for wind turbine application with a wind power class of 7 .

\section{REFERENCES}

[1] Emeis, S., Green energy and technology: wind energy meteorology, atmospheric physics for wind power generation, Springer, New York, 2013.

[2] Masseran, N.M., Markov Chain model for the stochastic behaviors of wind direction data, Energy Conversion and Management, vol. 92, 2015, p. 266-274.

[3] Jang, J.J., Lee, J.R., Analysis of design wind speed distribution of Taiwan Area, Journal of Marine Science Technology, vol. 5, no. 1,1997, p. 55-63.

[4] Kumaraswamy, B.G., Keshavan, B.K., Ravikiran Y.T., Analysis of seasonal wind speed and wind power density distribution in Aimangala wind form at Chitradurga Karnataka using two parameter weibull distribution function, Power and Energy Society General Meeting, 2011 IEEE, p. 1-4.

[5] Akpinar, E.K., Akpinar, S., Statistical analysis of wind energy potential on the basis of the weibull and rayleigh distributions for Agin-Elazig, Turkey, Proceedings of the Institution of Mechanical Engineers part A Journal of Power and Energy, vol. 218, no. 8, 2004, p. 557-565.

[6] Fatigun, A.T., Akoshile, C.O., Ajibola, T.B., Salau, R.O., Faweya, E.B., Aduloju, K.A., Oyedele, E.A., Evaluation of wind energy potential of Ikeja, Southwest, Nigeria using two-parameter weibull distribution function, IOSR Journal of Engineering, vol. 7, no. 9, 2017, p. 11-22.

[7] Udo, N.A., Oluleye, A., Ishola, K.A., Investigation of wind power over some selected coastal cities in Nigeria, Innovative Energy \& Research, vol. 6, no. 1, 2017, p. 156.

[8] Osatohanmwen, P., Oyegue, F.O., Ogbonmwan, M.S., Statistical analysis of wind energy potential in Benin City using the 2-parameter weibull distribution, International Journal of Renewable Energy \& Environment, vol. 2, 2016, p. 22-31.

[9] Dikko, I., Yahaya, D.B., Evaluation of wind power density in Gombe, Yola and Maiduguri, North eastern Nigeria, Journal of Research in Peace and Development, vol. 2, no. 5, 2012, p. 115-122.

[10] Sanusi, Y.K., Abioye, S.G., Estimation of wind energy potential in Southwestern Nigeria, The Pacific Journal of Science and Technology, vol. 12, no. 2, 2011, p. 160-166.

[11] Fadare, D.A., A statistical analysis of wind energy potential in Ibadan, Nigeria, Based on Weibull Distribution Function, The Pacific Journal of Science and Technology, vol. 9, no. 1, 2008, p. 110-119.

[12] https://support.minitab.com/en-us/minitab/18/help-and-how-to/probality-distribution-and-random-data/ supporting-topics/weibull-distribution/(12.03.2018)

[13] Seguro, J.V., Lambert, T.W., Modern estimation of the parameters of the weibull wind speed distribution for wind energy analysis, J. Journal of Wind Engineering \& Industrial Aerodynamics, vol. 85, 2000, p. 75-84. 
[14] Masseran, N., Razali, A.M., Ibrahim, K., An analysis of wind power density derived from several wind speed density functions: The regional assessment on wind power in Malaysia, Renewable and Sustainable Energy Reviews, vol. 16, no. 8, 2012, p. 6476-6487.

[15] Bolstad, B.M., Comparing some iterative methods of parameter estimation for censored gamma data, A dissertation submitted to the University Waikato in partial fulfillment of the requirements of the degree of Master of Science, 1998, bmbolstad.com/stuff/Bolstad_Waikato_1998.pdf (16.03.2018).

[16] Lo Brano, V., Orioli, A., Ciulla, G., Culotta, S., Quality of wind speed fitting distributions for the urban area of Palermo, Italy, Renewable Energy, vol. 36, no. 3, 2011, p. 1026-1039.

[17] Igwebuike, M.N., The suitability of statistical distribution in fitting maiduguri wind speed data, Nigeria Journal of Geography and Environment, vol.2, no. 1, 2011, p. 274-286.

[18] Masseran, N., Razali, A.M., Ibrahim, K., Zaharim, A., Sopian, K,. The probability distribution model of wind speed over East Malaysia, Research Journal of Applied Sciences, Engineering and Technology, vol. 6, no. 10, 2013, p. 1774-1779.

[19] Amaya-Martinez, P.A., Saavedra-Montes, A.J., Arango-Zuluaga, E.I., A Statistical analysis of wind speed distribution models in the Aburra Valley, Colombia. CT \& F-Ciencia, Tecnologia y Futuro, vol. 5, no. 5, 2014, p. 121-136.

[20] Massey, F.J., The Kolmogorov-Smirnov test for goodness of fit, Journal of the American Statistical Association, vol. 46, no. 253, 1951, p. 68-78.

[21] Cramer, H., On the composition of elementary errors, Scandinavian Actuarial Journal, vol. 1, 1928, p. 1374.

[22] Stephens, M.A., Goodness of fit for the extreme value distribution, Biometrika, vol. 64, no. 3, 1977, p. 583588.

[23] https://en.wikipedia.org/w/index.php?title=Mean_squared_error\&oldid=829132054 (19.03.2018).

[24] www.mathwave.com/easyfit/analysis/distributions/heading.html (19.03.2018).

[25] Mohammadi, K., Alavi, O., Mostafaeipour, A., Goudarzi, N., Jalilvand, M., Assessing different parameters estimation methods of weibull distribution to compute wind power density, Energy Conversion and Management, vol. 108, 2016, p. 322-335.

[26] Azad, A.K., Rasul, M.G., Yusaf, T., Statistical diagnosis of the best weibull methods for wind power assessment for agricultural applications, Energies, vol. 7, 2014, p. 3056-3085.

[27] https://www.stat.berkeley.edu/-vigre/activities/bootstrap/2006/wickham_stati.pdf (20.03.2018).

[28] ,https://scholarsachive.byu.edu/cgi/viewcontent.cgi?article-2927\&content=etd (12.03.2018).

[29] Oriaku, C.I., Osuwa, J.C., Asiegbu, A.D., Chukwu, G.U., Kanu, C.O., Frequency distribution analysis of available wind resources in Umudike, Abia State, Nigeria, for Wind Energy Conversion System Design, Pacific Journal of Science and Technology, vol. 8, no. 2, 2007, p. 203-206.

[30] https://rredc.nrel.gov/wind/pubs/atlas/titlepg.html (13.09.2018). 